\title{
Ocupación de pisos de altura y contexto de producción cerámica durante el Formativo: El caso de la región puneña de Chaschuil y su relación con el Bolsón de Fiambalá (Depto. Tinogasta, Catamarca, Argentina).
}

Norma Ratto, ${ }^{1}$ Martín Orgaz, ${ }^{2}$ Guillermo de la Fuente ${ }^{2}$ y Rita Plá ${ }^{3}$

\section{RESUMEN}

Se presenta nueva evidencia cerámica recuperada en pisos altitudinales de 4000 m.snm de la Puna Meridional catamarqueña, adscribiéndose a los Períodos Temprano y Medio (Formativo), tanto por estilo como por su caracterización tecnológica. El material cerámico se asocia a sitios arqueológicos reclamados en tiempos posteriores y/o a conjuntos de estructuras de planta circular, localizados en la cuenca superior del valle de Chaschuil (Laguna Salada, El Corral, Las Cuevas) y en áreas aledañas (Ojo de Las Lozas), respectivamente. Se discuten las relaciones sociales prehispánicas entre el área puneña y los valles mesotermales, especialmente el Bolsón de Fiambalá (1.500 m.snm), a través de los resultados del análisis por activación neutrónica realizado sobre muestras cerámicas y de fuentes de aprovisionamiento de materias primas cerámicas.

Palabras claves: cerámica formativa - contexto producción - relación puna y valle.

\section{ABSTRACT}

In this paper we present new evidence on the archaeological ceramic artefacts recovered in the Southern Andean Puna (Province of Catamarca) -at 4,000 m.asl-, ascribing, them to the Early and Middle Period (Formative Period), for both their stylistic and technological characteristics. The ceramic material was associated with archaeological sites that were re-utilized in later times, and/or circular stone structures located in the higher basin of the Chaschuil valley (Laguna Salada, El Corral, Las Cuevas) and in Las Lozas basin (Ojo de Las Lozas). We discuss the prehispanic social relations that existed between the Puna area and the mesothermal valleys, especially the Bolsón of Fiambalá (1,500 m.asl), relying on results obtained through the INAA (neutron activation analysis) of ceramic samples and raw materials.

Keywords: formative ceramic - production context - puna and valley relationship.

Recibido: febrero 2002. Manuscrito revisado aceptado: septiembre 2003.

1 Escuela de Arqueología (UNCa) y Sección Arqueología (ICA-FFyL-UBA), 25 de Mayo 217, Buenos Aires (1002). Email: nratto@ciudad.com.ar

\section{Introducción}

Actualmente, a la etapa Formativa se la concibe como un proceso que se manifiesta en forma diferencial según los antecedentes locales que le dan origen, incorporando un grado de participación y reelaboración ideológica que llega a integrar a gran parte del Noroeste Argentino, considerando al Formativo Superior como el primer desarrollo de Integración Regional (Pérez Gollán 1994a y 1994b; Pérez Gollán et al. 1996-1997; Assandri y Juez 1996). La nueva evidencia proveniente del valle de Ambato contextualiza en un mismo espacio y tiempo a tipos y estilos cerámicos, los que tradicionalmente fueron clasificados como característicos del Formativo Inferior -Ciénaga y Condorhuasi- y Formativo Superior -Aguada- con sus diferentes variantes. Por su parte, el rango temporal asignado tradicionalmente al Período Medio (650-850 DC), Formativo Superior, fue superado ampliamente con la nueva evidencia proveniente del valle de Ambato (Pérez Gollán 1994b; Assandri y Juez 1996-1997) y del valle central de Catamarca (Kriscautzky 1996-1997; González 1999), yuxtaponiéndose a los rangos temporales definidos tradicionalmente para los períodos Temprano (200 AC-650 DC) y Tardío (850-1480 DC) (González y Pérez Gollán 1976). Esto nos habla tanto de la dinámica del proceso como de la variabilidad interna de cada valle.

La amplia dispersión espacial de las sociedades del Formativo presenta variabilidad artefactual y ambiental, representadas por: a) diferentes patrones de asentamiento de uso doméstico residen-

2 Escuela de Arqueología (UNCa), Av. Belgrano 300, Catamarca (4700).

3 Técnicas Analíticas Nucleares. Comisión Nacional de Energía Atómica, Av. Del Libertador 8250, Buenos Aires (1429). Email: rpla@cae.cnea.gov.ar 
cial, doméstico rural y ceremonial; b) la presencia de un amplio espectro de estilos decorativos cerámicos, asociados a diferentes ámbitos geográficos; c) la ocupación y/o explotación de diferentes pisos ecológicos, desde los fondos de valle hasta las áreas cordilleranas, relacionados con la explotación de recursos complementarios; d) niveles de segregación y centralización relativamente bajos; e) con mecanismos de estratificación social y jerarquización política poco acentuados en sus inicios, pero que adquieren mayor complejización durante el desarrollo del proceso; y f) las relaciones con sociedades transandinas (Núñez R. y Tartusi 1993; Pérez Gollán 1994a y 1994b; González 1999; Núñez 1999; Olivera 2001, entre otros). Para el caso del proceso cultural Aguada, las nuevas hipótesis sugieren la existencia de un sistema de jefaturas o señoríos asociados a la presencia de ciertas formas de jerarquización social, unificados a nivel ideológico-religioso y posiblemente articulados en torno a redes de intercambio regional y trasandino (Sempé 1976; González 1977 y 1999; Núñez R. y Tartusi 1993; Pérez Gollán y Heredia 1987; Pérez Gollán et al. 1996-1997).

Las expresiones que caracterizaron al proceso cultural Aguada se extienden desde la Puna Norte catamarqueña hasta la provincia de San Juan al sur, y desde comienzos de la era hasta mediados el siglo XII. A pesar de tan amplia dispersión, con variabilidad ambiental y artefactual, determinadas áreas de la Puna Meridional catamarqueña, próximas al actual límite internacional ${ }^{4}$ entre las Repúblicas de Argentina y Chile, no contaban con información referida a la ocupación de esos espacios por parte de sociedades agroalfareras formativas -períodos culturales Temprano y Medio-. Sin embargo, en la región chilena del valle de Copiapó se encuentran documentadas las relaciones de los Complejos Molle y Animas con sociedades de los períodos Temprano y Medio del Noroeste Argentino, respectivamente (Niemeyer 1994; Castillo et al. 1996-1997; Niemeyer et al. 1997, entre otros).

La información para nuestra área de investigación comenzó a generarse con el Proyecto Arqueológico Chaschuil, ${ }^{5}$ sosteniéndose que la región

4 Límite internacional Paso San Francisco (4.700 m.snm).

5 Financiado por la Secretaría de Ciencia y Tecnología de la Universidad Nacional de Catamarca bajo la dirección de Norma Ratto. puneña de Chaschuil funcionó como un corredor de circulación de bienes, energía e información que interconectó diferentes ambientes con variados recursos, especialmente aquellos localizados en el Bolsón de Fiambalá, en la vertiente oriental de la Cordillera de los Andes y en la Puna Norte catamarqueña (Orgaz 1995; Ratto 1995 Ms, 1997 Ms, 1998 y 2000; Ratto y Orgaz 2000 Ms, entre otros). El proyecto busca explicar el proceso cultural prehispánico desde las sociedades con economía de retorno inmediato, hasta las de control estatal. Al respecto, se espera que los artefactos cerámicos recuperados en el área puneña hayan sido manufacturados con materias primas procedentes del área de valle, tanto durante el desarrollo de las sociedades con economías agropastoriles como estatal. Dentro de este contexto, el objetivo del trabajo es: a) dar a conocer una nueva área de dispersión del proceso desarrollado por las sociedades formativas en la Puna Meridional catamarqueña, y b) discutir el contexto de producción de sus bienes cerámicos, especialmente el área de aprovisionamiento de materias primas, en función de los resultados del análisis por activación neutrónica realizados sobre artefactos y muestras de depósitos arcillosos.

Los estudios de producción y distribución de artefactos cerámicos se vieron revitalizados con nuevas líneas de investigación que utilizaron técnicas analíticas para determinar su procedencia. El análisis por activación neutrónica instrumental (INAA) es una de esas técnicas que reúne los requisitos básicos de sensibilidad, precisión, exactitud y selectividad necesarios para la discusión de problemas arqueológicos de procedencia, comercio, intercambio y producción de alfarería, como así también para reconstruir las relaciones económicas inter e intra poblaciones del pasado (Bishop 1980; Bishop et al. 1982; Bishop y Neff 1989; Neff 1992 y 1998; Lizzie et al. 1995; Plá y Ratto 2000; Padilla 2001, entre otros). La interrelación de los resultados obtenidos por la vía de la caracterización multielemental, tanto de los tiestos como de los depósitos de materias primas cerámicas, más los aportados por el análisis tecnológico cerámico y las propiedades del registro, conforman el soporte para la discusión de las relaciones regionales en el marco de las hipótesis planteadas. De esta manera, la perspectiva de este trabajo interrelaciona arqueología, historia y ciencias físico-químicas para comprender cómo el comportamiento humano queda reflejado en los artefactos y sus distribuciones (Arnold et al. 1999). 


\section{Características ambientales de la región de Chaschuil}

La región en estudio se localiza en el extremo noroeste del Departamento de Tinogasta, Catamarca. Comprende las cabeceras del valle de Chaschuil y sus cuencas hídricas aledañas $(\mathrm{Ca}-$ zadero Grande, Las Lozas y San Francisco). La región se caracteriza por una alta topografía relativa, con cotas altitudinales que varían entre los 3.500 a $4.700 \mathrm{~m} . s n m$ en gradiente sur-norte, presentando características fitogeográficas de los Distritos de Puna y Altoandino (Cabrera y Willink 1973; Morlans y Guichón 1995; Martínez Carretero 1995; Noetinger 1996 Ms). Los límites geográficos del área son: al norte el cordón de San
Buenaventura, que coincide con el límite departamental entre Antofagasta de la Sierra y Tinogasta; al sur el límite es arbitrario y está fijado por la cota altitudinal (3.500 m.snm); al este se encuentra el cordón montañoso de Las Planchadas que divide a la región del valle de Abaucán, y finalmente al oeste la Cordillera de los Andes, límite internacional con la República de Chile (Figura 1 y Tabla 1).

Existen diferentes criterios geológicos para determinar los límites geográficos de la región meridional puneña, los que se basan en el concepto de unidad geográfica (Aceñolaza y Toselli 1981; Turner 1967) y estructural (Navarro 1990). Si bien la Cordillera de San Buenaventura, con su direc-

\begin{tabular}{|c|c|}
\hline $\begin{array}{l}\text { SITIOS ARQUEOLOGICOS DEL AREA } \\
\text { PUNEÑA DE CHASCHUIL }\end{array}$ & $\begin{array}{l}\text { SITIOS ARQUEOLOGICOS DEL BOLSON } \\
\text { DE FIAMBALA - VALLE ABAUCAN }\end{array}$ \\
\hline $\begin{array}{ll}1 & \text { El Corral y Las Cuevas }(4.000 \mathrm{~m} . \mathrm{snm}) \\
2 & \text { Laguna Salada (3.980 m.snm) } \\
3 & \text { Ojo de Las Lozas }(4.000 \mathrm{~m} . \mathrm{snm})\end{array}$ & $\begin{array}{ll}5 & \text { Palo Blanco }(1.980 \mathrm{~m} . \mathrm{snm}) \\
6 & \text { Batungasta }(1.500 \mathrm{~m} . \mathrm{snm})\end{array}$ \\
\hline
\end{tabular}

Tabla 1. Sitios de procedencia de la muestra cerámica.

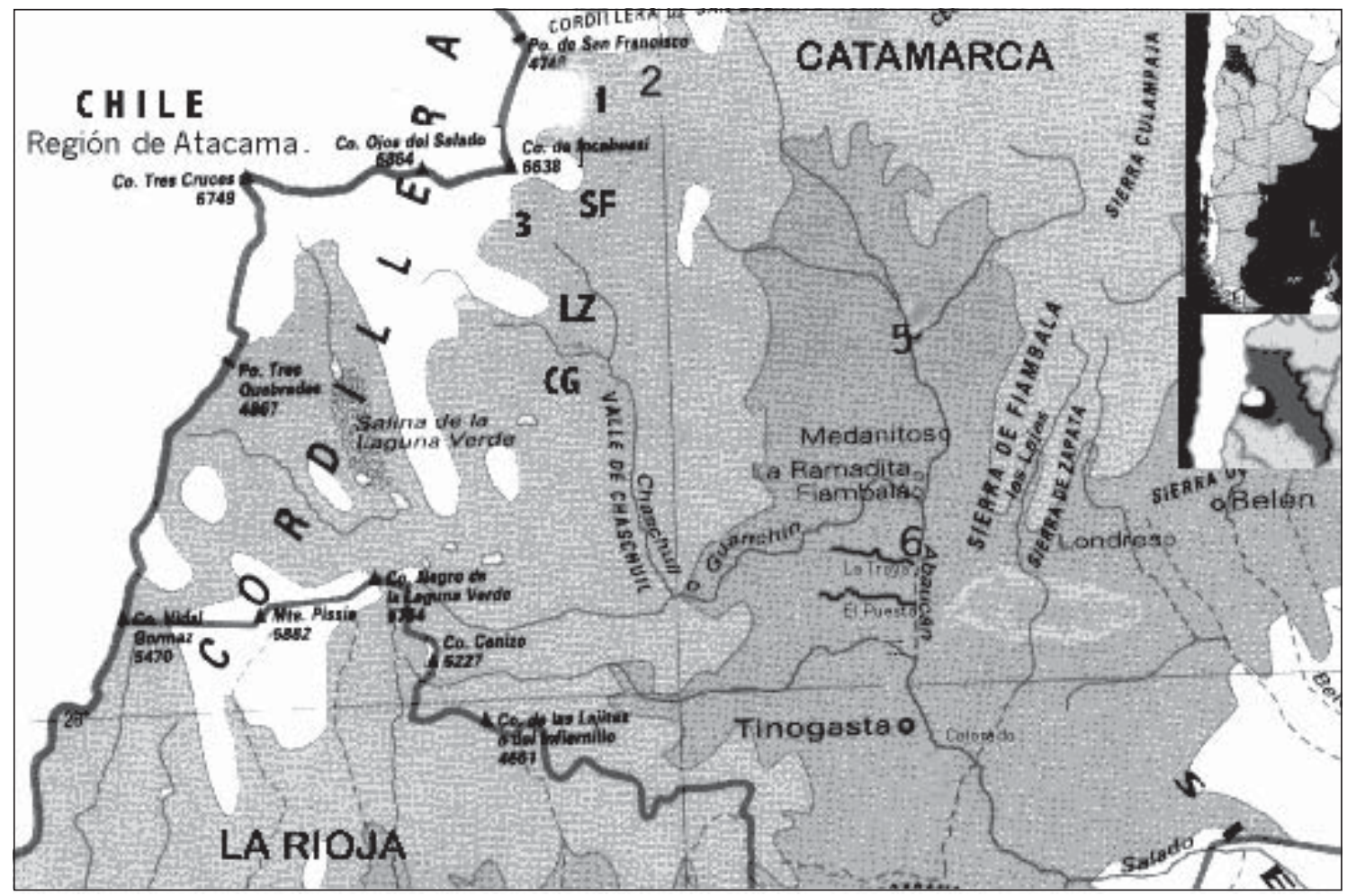

Figura 1. Localización del área de estudio y de los sitios de procedencia de la muestra cerámica (SF: San Francisco; LZ: Las Lozas y CG: Cazadero Grande). Escala aproximada 1: 17.000. 
ción oeste-este, constituye una estructura de contraste, los territorios localizados al sur de ésta se presentan como una transición cordillerana catamarqueña, caracterizada por presentar iguales rellenos sedimentarios que la Puna al norte de San Buenaventura y los Andes Centrales (Argerich 1976; Costello 1993). Por lo tanto, se considera que la región de Chaschuil está comprendida dentro de la Puna Meridional, tanto por sus características fitogeográficas como por sus particularidades geológicas estructurales.

Las fuerzas tectónicas que generaron la cordillera andina estimularon la aparición de otros relieves relativos de menor altitud, como así la formación de depresiones alargadas como el valle de Chaschuil. Este, en su curso superior, presenta tres cuencas hídricas tributarias del río Chaschuil o Guanchín, separadas entre sí 40 a 50 km lineales, aproximadamente: San Francisco (SF-4.000 m.snm), Las Lozas (LZ-3.800 m.snm) y Cazadero Grande (CG-3.500 m.snm). Estas cotas identifican el nivel de base, ascendiendo con gradiente este-oeste hasta alcanzar sus cabeceras en la cordillera andina. Asimismo, existen cursos temporarios originados por los deshielos de las altas cumbres, cuya acción como modeladora del paisaje depende de las características texturales del sustrato. Ratto (1995 Ms, 1997 Ms, 1998 y 2000) caracteriza a la región de Chaschuil como una combinación de relieves abruptos-montañosos, y llanos que corresponden a la zona cordillerana y a las vegas y pampas, respectivamente. Los espacios de menores alturas relativas se comportan como depresiones encerradas por espacios de mayor altura relativa. Esta diferenciación tiene su correlato geológico, ya que las áreas cordillerana y las depresiones se caracterizan por la presencia de estratos volcánicos (andesitas, basaltos y piroclásticos) y acumulaciones dentríticas modernas, respectivamente.

Por su parte, la latitud y altitud conforman un clima semidesértico, donde los principales agentes de modelación del paisaje son la gravedad, el viento y el agua. Las actuales características de este ambiente son (Morlans $1985 \mathrm{Ms}$ ): a) déficit de agua durante la mayor parte del año; b) irregularidad en las precipitaciones; c) humedad atmosférica muy baja; d) gran radiación solar; e) temperaturas nocturnas inferiores a $0^{\circ}$ durante todo el año; f) amplitud térmica diaria; g) abundancia de sales solubles, y h) suelos rocosos y pedrego- sos-arenosos y frecuentes fenómenos de solifluxión. Estas características generan una lenta evolución del sustrato y una escasa descomposición orgánica. Los resultados del relevamiento eco-topográfico y muestreos fisionómicos realizados en la región de Chaschuil marcan tendencias que se relacionan positivamente con lo expresado anteriormente (Ratto 1995 Ms, 1997 Ms y 2000; Noetinger 1996 Ms). Las características eco-topográficas reseñadas determinan que las geoformas (vega, pampas, pedemontes, entre otras) presenten, en general, alta visibilidad y obstrusividad arqueológica (sensu Wandsnider y Camilli 1992), permitiendo la observación, recuperación y registro de artefactos y estructuras.

La Puna puede ser clasificada dentro de los ambientes con recursos distribuidos heterogéneamente, caracterizándose por la presencia de zonas de concentración de nutrientes, definidas como áreas donde se halla disponible una amplia gama de recursos dentro de espacios geográficos con límites precisos. En estas áreas, las estrategias apuntan principalmente a explotar la diversidad de los loci y sus recursos, necesitándose para esto fuentes de agua, abundante biomasa animal, fuentes de materias primas y afloramientos rocosos para fines diversos (Yacobaccio 1991 y 1994). Al respecto, la región puneña de Chaschuil presenta recursos de diferente índole y abundancia, pudiéndose mencionar:

a) Alta frecuencia relativa de camélidos sudamericanos silvestres, cuyo potencial cuantitativo puede estimarse a través del relevamiento de vicuñas y guanacos realizado en el sector superior de la cuenca de Cazadero Grande, entre 4.000 a 4.750 m.snm. De acuerdo a las observaciones y mediciones realizadas dentro de una superficie de 800 $\mathrm{km}^{2}$ se registró una densidad de 0.95 y 0.64 de vicuñas y guanacos por $\mathrm{km}^{2}$, respectivamente (Scala et al. 1995a y 1995b).

b) Fuentes de aprovisionamiento de materias primas líticas locales y regionales a nivel intracuenca e intercuenca, respectivamente (Luna 1996; Ratto 2000). Las canteras localizadas muestran propiedades aptas para la talla, presentándose en cantidad abundante y concentrada (sensu Nami 1992).

c) Depósitos de materias primas cerámicas de baja disponibilidad pero de alta plasticidad y trabajabilidad, especialmente en la cota de 3.500 
m.snm (CG). Se trata de arcillas secundarias, meteorizadas y/o transportadas y depositadas de acuerdo con las características geomorfológicas y geológicas de las áreas de recuperación (De La Fuente 1997 Ms; Plá y Ratto 2000).

d) Materias primas vegetales para distintos usos, pudiéndose mencionar: i) energéticas para combustión (Adesmia echinus y Adesmia nanolignea -cuerno de cabra-, Lampaya hieromyni -lampaya; ii) tecnológicas (Scirpus nevadensis -junquilloy Juncus balticus -junco); iii) medicinales (Acantolippia punensis -rica-rica; y iv) techumbre (Deyeuxia sp. -paja brava), entre otras de usos desconocidos. Su abundancia y disponibilidad varían intercuencas, pero fueron registradas a nivel regional (Ratto 1995 Ms y 1997 Ms).

En resumen, la región puneña de Chaschuil presenta una alta topografía relativa, constituyéndose en un limitante y condicionante para el uso del espacio y comunicación entre zonas, y recursos distribuidos en forma heterogénea con zonas de concentración en oposición a otras donde se presentan dispersos, siendo los primeros aptos para la instalación humana en el tiempo.

\section{La región de Chaschuil como un corredor de bienes, energía e información en el tiempo}

El registro arqueológico presenta un enorme rango de variación en su estructura y patrón organizativo, conformando sucesivos paisajes arqueológicos que reflejan condicionamientos ambientales, económicos, sociopolíticos e ideológicos que pueden ser abordados desde diferentes posturas teóricas (Crumley y Marquardt 1991; Criado 1997; Rossignol y Wandsnider 1992; Lanata 1997, entre otros).

El análisis del paisaje arqueológico permite explicar la utilización del espacio por sociedades del pasado, centrando su estudio entre los puntos de concentración artefactual diferencial. Para la región puneña de Chaschuil se espera que las sociedades con diferentes organizaciones sociopolíticas reocuparan en el tiempo los espacios favorecidos con mayor concentración de recursos. El correlato material en el registro arqueológico se representa a través de diferencias en las distribuciones artefactuales, las que reflejan diferentes estrategias productivas desarrolladas en el tiempo. A través de las propiedades del registro ar- queológico es posible modelar las diferencias o similitudes en el uso del espacio desde su dimensión física y social (Ratto 2003).

La estructura del registro arqueológico regional permite sostener que la región de Chaschuil funcionó en el pasado como un corredor para la circulación de bienes, energía e información. Los loci de mayores densidades artefactuales se comportaron como nodos de una red que interconectaron diferentes espacios e instalaciones de sociedades agroalfareras y estatales, tanto a escala regional como macrorregional. A saber:

1. En la escala regional, la ocupación del espacio por parte de sociedades agroalfareras se caracterizó por la presencia de sitios discretos, aprovechando las formaciones rocosas localizadas en el borde de las vegas de altura y sectores deprimidos de la región puneña (4.000 m.snm), habiendo realizado una formatización arquitectónica mínima del espacio. En cambio, durante la ocupación incaica el espacio fue modificado en forma diferente mediante la construcción de instalaciones con rasgos propios, localizadas sobre o en las adyacencias de las ocupaciones previas. Estos emplazamientos se caracterizan por constituir una red logística que articula las zonas puneñas deprimidas con los santuarios ${ }^{6}$ de las altas cumbres (Ratto y Orgaz 2000 Ms). La reocupación del espacio en el tiempo generó procesos de reclamación (sensu Schiffer 1987) ${ }^{7}$ de los sitios arqueológicos con arquitectura, pudiéndose registrar casos diferentes, por ejemplo:

a) En la cota de $4.000 \mathrm{~m} . \mathrm{snm}$ (SF), las instalaciones pre-incas fueron modificadas por los incas, y éstas por pastores históricos. Esto se refleja en

6 La presencia de santuarios de altura, en la cima de las altas cumbres, le otorga una dimensión particular al espacio dentro de la cosmovisión inca, donde la expansión territorial quedaba plasmada a través de la posesión ritual del espacio geográfico y político. Así, el contextualizar los sitios arqueológicos con las características del paisaje natural, permite modelar el perfil de "paisaje ritual" (sensu Broda 2000) aprehendido por las sociedades prehispánicas en los territorios incorporados durante la expansión del incanato.

7 Por "reclamado" Schiffer se refiere a un proceso de formación cultural que da cuenta de la reutilización y/o reocupación de un espacio por parte de organizaciones sociales diferentes. En este caso particular, los sitios del Formativo, con un patrón arquitectónico característico fueron "reclamados" en tiempos posteriores, especialmente por los incas. 
que aquellas con patrón de Rectángulo Perimetral Compuesto (RPC) se encuentran en cimientos, en asociación a un corral histórico (a $35 \mathrm{~m}$ ) en perfecto estado de conservación, adosado a un afloramiento rocoso. Sin embargo, el material cerámico superficial corresponde mayoritariamente a estilos pertenecientes a los períodos Temprano y Medio, especialmente en las proximidades del área modificada por el corral. Mediante las excavaciones sistemáticas realizadas, tanto en la instalación inca San Francisco como en El Corral, se obtuvieron fragmentos cerámicos clasificados dentro de los estilos Inca y Ciénaga, respectivamente. En la base de la última línea de piedra correspondiente a los cimientos del recinto $\mathrm{n}^{\mathrm{o}} 10$ de la instalación inca San Francisco (Ratto y Orgaz 2000 Ms), se detectó un área de rubefacción con carbones dispersos, habiéndose obtenido las siguientes fechas radiocarbónicas: i) Muestra LP716 Edad Radiocarbónica $1030 \pm 60$ años $\mathrm{C}^{14}$ AP, y ii) Muestra LP-676 Edad Radiocarbónica $940 \pm 80$ años $C^{14}$ AP. Estas fechas tan tempranas apoyan la idea de que la instalación inca se asentó sobre una ocupación anterior. Asimismo, fragmentos cerámicos de superficie recuperados de una misma geoforma y unidad de muestreo, pertenecientes a estilos cerámicos diferentes, arrojaron fechados por termoluminicencia que abarcan un lapso desde el $1265 \pm 65$ al $550 \pm 65$ años AP (Tabla 2).

b) En otra área de la cuenca de SF, distantes aproximadamente $2 \mathrm{~km}$ al norte del caso anterior, se localiza el sitio arqueológico Laguna Salada compuesto por estructuras de patrón circular asociadas al borde de vega, las que se encuentran en muy mal estado de conservación debido a la acción antrópica reciente. Las estructuras están asociadas a otro afloramiento rocoso que presenta aleros, algunos de los que han sido tapiados en tiempos recientes utilizando piedras de las estructuras mencionadas. En superficie se registra alta densidad de fragmentos cerámicos, mayoritariamente pertenecientes a los Períodos Temprano y Medio. De las excavaciones sistemáticas realizadas en las estructuras de patrón circular se recuperó material cerámico adscrito al estilo ciénaga, obteniéndose por termoluminicencia una fecha de $1315 \pm 130$ años AP (Tabla 2).

c) Aproximadamente a $1.5 \mathrm{~km}$ al sudeste de la instalación inca San Francisco se encuentra el área de Las Cuevas, también localizada dentro de la cuenca SF y asociada a un afloramiento rocoso. El área fue sujeta a una alta modificación como producto de la instalación de un campamento minero en las década de los ' 30 . Los aleros u oquedades naturales fueron alterados por la construcción de dependencias, habiéndose cementado sus bases. De las excavaciones realizadas en uno de los aleros profundos, sin modificación aparente, se recuperó cerámica en baja frecuencia, por cuyas características tecnológicas puede ser adscrita a sociedades agroalfareras de la etapa Formativa.

d) El curso superior del río Las Lozas (LZ) es donde mejor queda testimoniada la reclamación de sitios en la región de Chaschuil. El sitio arqueológico se localiza a una altitud de 4.000 m.snm (Ojo de Las Lozas), ${ }^{8}$ distante aproximadamente $30 \mathrm{~km}$ lineales en dirección norte de los casos anteriores. El ambiente físico es similar a las vegas de SF, localizadas en la misma cota, especialmente por la presencia de afloramientos rocosos en las adyacencias de las vegas de altura. Se registró una instalación conformada por 33 recintos circulares, cuyos diámetros varían entre 2 a $3.5 \mathrm{~m}$, dispuestos en el talud o base del afloramiento rocoso, conformando conjuntos de 2 a 5 recintos, separados entre sí por una distancia de 5 $\mathrm{m}$, aproximadamente. En la periferia este del sitio fueron registrados recintos asociados, de forma subcuadrangular y rectangular, alterados por derrumbes del afloramiento rocoso y acción antrópica. ${ }^{9}$ Toda el área está sujeta a un intenso proceso de acumulación por acción eólica, afectando en algunos casos la delimitación precisa de los recintos por hallarse sectores totalmente colmatados. Asimismo, la frecuencia de material cerámico en superficie es muy baja, principalmente debido a la misma causa, correspondiendo a los períodos Temprano e Inca. Aún no han sido realizadas excavaciones sistemáticas, considerándose para el análisis sólo material cerámico de superficie.

2. A escala macrorregional, el corredor comunica con otros espacios y ambientes, tanto en actuales

8 El Ojo de Las Lozas (4.000 m.snm) se localiza a $18 \mathrm{~km}$ (lineales) desde el nivel de base del río Las Lozas (3.800 m.snm).

9 Posiblemente debido a la acción de andinistas, dado que utilizan el lugar como campamento temporal dentro de una de las rutas de ascenso al cerro Incahuasi (6.730 m.snm). 


\begin{tabular}{|c|c|c|c|c|c|}
\hline MUESTRA & $\begin{array}{c}\text { ESTILO FRAGMENTO CERAMICO } \\
\text { Y PROCEDENCIA }\end{array}$ & P (GY) & $\begin{array}{c}\text { D } \\
\text { (GY/AÑ) }\end{array}$ & $\begin{array}{c}\text { AÑOS ANTES } \\
\text { DEL PRESENTE }\end{array}$ & $\begin{array}{c}\text { RANGO AÑOS } \\
\text { CALENDARIOS }\end{array}$ \\
\hline UCTL 1305 & $\begin{array}{c}\text { Incaico } \\
\text { RT6/1-126 }\end{array}$ & 2.67 & 0.00485 & $550 \pm 55$ & $1400-1500$ DC \\
UCTL 1306 & $\begin{array}{c}\text { Aguada } \\
\text { RT6/1-294 } \\
\text { UCTL 1307 }\end{array}$ & 3.80 & 0.00411 & $925 \pm 90$ & $985-1165$ DC \\
Ciénaga \\
RT 6/1 292 1308 & $\begin{array}{c}\text { Ciénaga } \\
\text { L 4/1-540 }\end{array}$ & 5.96 & 0.00392 & $1265 \pm 120$ & $615-855$ DC \\
\hline
\end{tabular}

Tabla 2. Fechas por termoluminicencia de fragmentos cerámicos de superficie.

territorios chilenos como argentinos. $\mathrm{Al}$ respecto, se menciona el valle de Copiapó en Chile, como las localidades en territorio argentino de Antofagasta de la Sierra y Antofalla, además de los valles de Abaucán y los sectores medio e inferior del valle de Chaschuil. Por lo tanto, la circulación adquiere modalidades transversales y longitudinales, permitiendo integrar grandes espacios. En el caso de la ocupación inca, distintas instalaciones estatales pueden interconectarse a través del espacio del curso superior del valle de Chaschuil, localizadas en Antofagasta de la Sierra, el valle de Abaucán, el Bolsón de Fiambalá y el valle de Copiapó, en territorio chileno (Ratto y Orgaz $2000 \mathrm{Ms}$ ). De igual manera, en tiempos preincas sitios arqueológicos localizados en esas áreas pueden interconectarse a través de la región de Chaschuil, como ser: i) Palo Blanco y Saujil (Sempé 1976 y 1977a) en el valle de Abaucán; ii) el sector norte del río La Troya en el Bolsón de Fiambalá (Ratto $1995 \mathrm{Ms}$ ), y iii) sitios de los Complejos Molle y Animas del valle de Copiapó, en Chile (Niemeyer 1994; Castillo et al. 19961997; Niemeyer et al. 1997, entre otros).

En resumen, la región puneña de Chaschuil presenta baja densidad cerámica asociada a pequeñas instalaciones con evidencia de procesos de reclamación por reocupación del espacio en el tiempo, constituyéndose en un conector entre diferentes eco-zonas. En esta primera instancia sólo estamos en condiciones de calibrar las relaciones entre Puna y el valle mesotermal (Bolsón de Fiambalá) a través de la realización de análisis por activación neutrónica sobre material cerámico recuperado en ambas regiones.

\section{Composición de la muestra cerámica y características tecnológicas}

a) Procedencia de la muestra. La muestra cerámica sujeta a análisis tecnológicos y analíticos está compuesta por 95 tiestos procedentes de sitios arqueológicos localizados en el área puneña de Chaschuil $(n=62)$ y del valle mesotermal de Abaucán (n=33) (Tabla 3 y Figura 1). La muestra fue clasificada como perteneciente al Período Temprano o Medio, en función de sus características tecnológicas y estilísticas.

El material cerámico puneño $(n=62)$ proviene de los sitios arqueológicos Laguna Salada (27:62), El Corral (24:62), Las Cuevas (3:62) y Ojo de Las Lozas (8:62), tanto de superficie como de excavación. Por su parte, para corroborar la hipótesis de las relaciones a nivel macrorregional entre el área de Puna y el valle mesotermal (Bolsón de Fiambalá), distantes una de otra $100 \mathrm{~km}$ lineales, se seleccionó una serie de tiestos para su análisis tecnológico y analítico $(n=34)$. A saber:

i) 20 fragmentos cerámicos provienen de los muestreos sistemáticos realizados dentro del área de dispersión artefactual del sitio arqueológico de Batungasta (Sempé 1977b). Este se localiza en cota de $1.500 \mathrm{~m}$.snm en el margen derecho del río La Troya (Depto. Tinogasta, Catamarca). Se realizaron transectas radiales, con centro en el sitio, habiéndose muestreado una superficie equivalente a $9.000 \mathrm{~m}^{2}$ (Ratto 1996 Ms y 1997 Ms).

ii) 14 fragmentos cerámicos provienen del sitio arqueológico Palo Blanco (2.300 m.snm) localizado en el valle de Abaucán (Figura 1). Su 


\begin{tabular}{|c|c|c|c|c|c|}
\hline \multirow{2}{*}{$\begin{array}{l}\text { SITIO } \\
\text { ARQUEOLOGICO }\end{array}$} & \multirow{2}{*}{$\begin{array}{c}\text { CANTIDAD } \\
\text { TOTAL DE } \\
\text { FRAGMENTOS }\end{array}$} & \multicolumn{2}{|c|}{ PUNA } & \multicolumn{2}{|c|}{ VALLE } \\
\hline & & $\begin{array}{c}\text { PERIODO } \\
\text { TEMPRANO }\end{array}$ & $\begin{array}{c}\text { PERIODO } \\
\text { MEDIO }\end{array}$ & $\begin{array}{c}\text { PERIODO } \\
\text { TEMPRANO }\end{array}$ & $\begin{array}{l}\text { PERIODO } \\
\text { MEDIO }\end{array}$ \\
\hline El Corral (P) & 24 & 15 & 9 & - & - \\
\hline Laguna Salada (P) & 27 & 23 & 4 & - & - \\
\hline Las Cuevas $(\mathrm{P})$ & 3 & 3 & 0 & - & - \\
\hline Ojo Las Lozas (P) & 8 & 7 & 1 & - & - \\
\hline Batungasta (V) & 20 & - & - & 12 & 8 \\
\hline Palo Blanco (V) & 14 & - & - & 14 & 0 \\
\hline Totales & 96 & 48 & 14 & 26 & 8 \\
\hline \multirow{2}{*}{\multicolumn{2}{|c|}{$\begin{array}{l}\mathrm{P}=\text { Puna } \\
\mathrm{V}=\text { Valle }\end{array}$}} & \multicolumn{2}{|c|}{62} & \multicolumn{2}{|c|}{34} \\
\hline & & \multicolumn{4}{|c|}{9} \\
\hline
\end{tabular}

Tabla 3. Composición de la muestra cerámica analizada por activación neutrónica.

inclusión responde a los objetivos del trabajo, ya es considerado un fiel representante del desarrollo Formativo para el valle mencionado (Sempé 1977a).

b) Características tecnológicas del conjunto cerámico. Todos los tiestos fueron revisados por especialistas para confirmar su adscripción y analizados mediante lupa binocular de bajos aumentos. El conjunto cerámico Formativo puneño está representado por:

i) Ciénaga geométrico inciso, gris pulido, pintura rojo sobre crema, liso oxidante y liso reductor;

ii) Saujil gris lisa, pulido en bandas y tosco;

iii) Condorhuasi (Río Diablo) y;

iv) Aguada lisa y pintura rojo sobre ante.

El tamaño pequeño de los tiestos dificulta y/o imposibilita su adscripción a un tipo determinado de forma y/o parte de la vasija. En general, la proporción de inclusiones minerales es menor a un $10 \%$ sobre el total de la pasta. El cuarzo es el mineral más representado teniendo diferentes tamaños granulométricos. Es posible que constituya un componente natural de los bancos de arcilla utilizados para la manufactura. El resto de los minerales se registran en menores proporciones, mencionándose feldespatos, micas, tiestos molidos y fragmentos de roca, especialmente en los tiestos sin decoración adscritos al Período Temprano. El tamaño del antiplástico observa mayor variabilidad en este último grupo de tiestos, variando desde muy fino a muy grueso, mientras que en el resto de la muestra es predominante- mente de tamaño fino. La cocción reductora y oxidante predomina para los tiestos del Período Temprano y Medio, respectivamente.

Por su parte, el conjunto cerámico Formativo del valle está representado por:

i) Ciénaga geométrico inciso, gris pulido y pintura rojo sobre crema;

ii) Candelaria;

iii) Condorhuasi (Río Diablo);

iv) Aguada característica del sector Septentrional y Meridional (González 1999), presentando pintura negro y rojo, pulida y modelada y;

v) un caso de inciso modelado de posible filiación transandina pero que, en conjunto, guarda características tecnológicas con los del Período Temprano.

Todos los tiestos fueron revisados por especialistas (ver nota 9) para confirmar su adscripción y ser analizados mediante lupa binocular de bajos aumentos. La carga de las inclusiones minerales no supera el 7\% promedio. El cuarzo está representado en toda la muestra, con diferentes tamaños granulométricos, aunque en menor proporción respecto a la muestra puneña. No se descarta que pueda constituir un componente natural de los bancos de arcilla utilizados para la manufactura. El resto de los minerales se registra en bajas proporciones, mencionándose calcita, micas y fragmentos de rocas, y aún menos los feldespatos, vidrio y tiestos molidos, estos últimos especialmente en los tiestos adscritos al Período Temprano. El tamaño del antiplástico varía entre fino y muy fino para toda la muestra, mientras que la 
cocción es exclusivamente oxidante para los tiestos Aguada, agregándose también la reductora para el caso de los tiestos tempranos.

c) Grupos (clusters) tecnológicos de la muestra de tiestos de Puna y valle. Es posible modelar la estructura adoptada por la similitud o distancia entre los objetos según su valor, representado a través de las variables usadas en su descripción. Para ello se emplean métodos de análisis de conglomerados o análisis de clusters para agrupar objetos similares en el mismo conglomerado o grupo. En otras palabras, la técnica permite formar grupos que se asocian en función de su grado de similitud. Los resultados se representan a través de un dendrograma que muestra las relaciones entre individuos y grupos. Debe tenerse presente que los diferentes métodos existentes para definir los grupos tienden a imponer su propia estructura en los datos. En este trabajo se utiliza el método jerárquico y la técnica aglomerativa (Crisci y López 1983; Shennan 1992).

El dendrograma de la Figura 2 muestra los grupos que se conforman cuando se interrelaciona a los tiestos procedentes de Puna y valle $(n=96)$ en función de:

i) el porcentaje de antiplástico representado a través de la carga de las inclusiones mineral;

ii) el porcentaje de matriz, y;

iii) el tamaño del antiplástico.

Se utilizó el método Ward, Cuadrado de la Distancia Euclideana y normalización de los valores de las variables entre 0-1. El nivel elegido informa acerca del estilo cerámico y la procedencia de los tiestos. El análisis estadístico genera la definición de cinco grupos que presentan distinto grado de similitud entre sí, conformando dos grupos principales:

a) Los conjuntos 1 y 3 presentan semejanza en las variables tecnológicas consideradas, conformando un grupo mayor con alto grado de homogeneidad que incluye el $75 \%$ de la muestra (72:96). Esta está compuesta tanto por tiestos de puna como de valle adscritos a los períodos Temprano y Medio (Figura 3). El conjunto 1 presenta la menor carga de atemperantes, constituyendo pastas compactas con alta presencia de cuarzo de tamaño muy fino en valores menores al 5\%. La diferencia con el conjunto 3 radica en que pre-

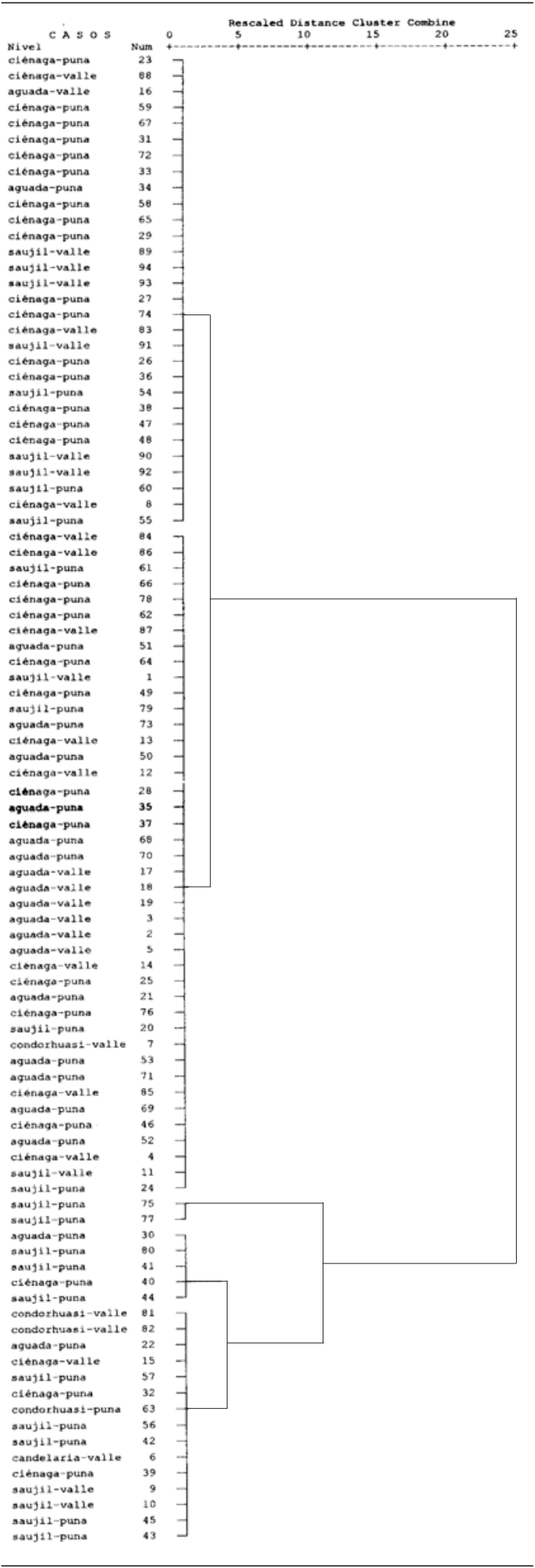

Figura 2. Dendrograma de variables tecnológicas de la muestra cerámica. 
senta mayor carga de atemperantes, alrededor del $10 \%$, también con presencia predominante de cuarzo de tamaño fino y muy fino, acompañado por muy baja representatividad de mica y fragmentos de roca. La cocción en ambos conjuntos es tanto oxidante como reductora.

b) El resto (24:96) define un grupo con alto nivel de similitud que está compuesto por los conjuntos 2 y 4; que a su vez se relacionan con el conjunto 5 (sólo dos casos) a un nivel de similitud menor. En estos tres conjuntos no están representados los tiestos del Período Medio (Aguada) procedentes del valle, mientras que los del Período Temprano de igual procedencia sólo están incluidos en el conjunto 2 (Figura 3). El conjunto 2 presenta una carga de atemperantes que oscila en el $20 \%$ de tamaño variado; mientras que en el conjunto 4 asciende al 40\%, con tamaños de medio a muy grueso. En ambos casos las principales inclusiones minerales son cuarzo, fragmentos de rocas, mica y feldespatos, presentando tanto cocción oxidante como reductora. Por su parte, los fragmentos del conjunto 5 presentan la mayor carga atemperante de la muestra (45\%) compuesta principalmente por cuarzo y mica de tamaños grueso a muy grueso y presentan cocción reductora.

En resumen, la muestra cerámica analizada presenta variabilidad tecnológica, habiendo sido definidos cinco conjuntos mediante la aplicación de técnicas estadísticas multivariadas (Figura 2). Cada

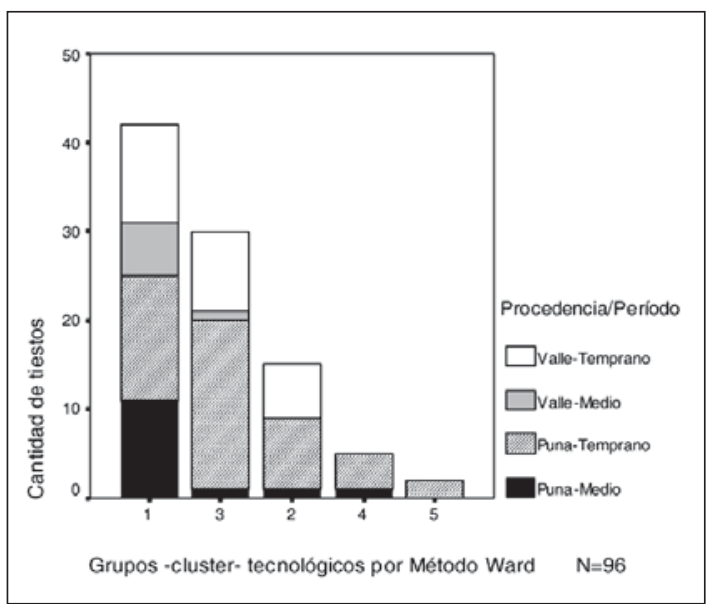

Figura 3. Procedencia y período cultural de los tiestos que conforman cada uno de los conglomerados tecnológicos definidos por Método Ward. uno incluye tiestos adscritos tanto al Período Temprano como al Medio (Figura 3), los que provienen de sitios arqueológicos localizados en el área puneña (Chaschuil) y el valle mesotermal (Bolsón de Fiambalá). Los conjuntos se relacionan entre sí a distintos niveles de similitud, conformando dos grupos principales que contrastan por la carga de atemperantes presentes, principalmente cuarzo, y el tamaño y porcentaje de las inclusiones minerales.

\section{Aprovisionamiento de materias primas cerámicas: Características de los depósitos de Puna y valles}

El estudio de la variabilidad ambiental de materias primas cerámicas, tanto a nivel regional como macrorregional, proporciona la vía de entrada para discutir problemas arqueológicos de procedencia, disponibilidad, significación económica y estrategias de explotación desarrolladas en el pasado, a través de la realización de baterías de análisis y técnicas sobre las muestras de los depósitos muestreados (testeos de campo, análisis texturales y granulométricos, difracción de rayos $\mathrm{X}$ y análisis por activación neutrónica).

Del muestreo de materias primas cerámicas se obtuvo 54 muestras, tanto para el área puneña en estudio (9:54) como en el valle mesotermal del Abaucán (45:54) (Bolsón de Fiambalá), abarcando los ríos La Troya (1.500 m.snm), El Puesto (1.465 m.snm), Guanchín (desde los 3.000 a 1.500 m.snm) y Colorado (1.500 m.snm), que alimentan la cuenca mencionada. Las características de las materias primas cerámicas (plasticidad, trabajabilidad, disponibilidad, fracción textural y minerales arcillosos) procedentes de las áreas de Puna y valle, evidencian la existencia de diferencias importantes en cuanto a la disponibilidad, constitución y calidades para la manufactura de cerámica.

Los depósitos arcillosos procedentes de la región de Chaschuil constituyen arcillas secundarias, meteorizadas y/o transportadas y depositadas en ambientes de energía variable, de acuerdo con las características geológicas y geomorfológicas de la región. En general, la región presenta baja disponibilidad de depósitos arcillosos, con alta representación de la fracción textural arenosa y alta plasticidad y trabajabilidad. Los resultados de los análisis de difracción de rayos $X(n=9)$ determi- 
nan que sólo las muestras procedentes de Cazadero Grande presentan buena calidad para la manufactura cerámica, caracterizándose por bajas concentraciones de minerales arcillosos (10-25\%), y por altas y medias proporciones relativas de calcita y feldespato, respectivamente (De La Fuente $1997 \mathrm{Ms}$ ).

Los depósitos arcillosos procedentes del río La Troya $(n=18)$ son constituidos por arcillas secundarias, meteorizadas y transportadas por agentes fluviales en un ambiente netamente sedimentario. En general, la región presenta alta disponibilidad de materias primas cerámicas, con excelentes propiedades de plasticidad y trabajabilidad para la manufactura cerámica. Los resultados obtenidos de los análisis de difracción de rayos $\mathrm{X}$ indican que todas las muestras son de buena calidad, presentando alto porcentajes de arcilla (17\%-45\%) con importantes concentraciones de minerales arcillosos (Esmectita-Montmorillonita e Illita). Además, presentan porcentajes relativamente bajos de feldespatos $(10 \%-25 \%)$ y calcita $(2 \%-5 \%)$ y altos de cuarzo (24-45\%), indicando que estas inclusiones minerales constituyen un antiplástico natural de la formación del depósito (De La Fuente 1997 Ms). Los depósitos de El Puesto ( $n=5)$ y Colorado $(n=3)$ presentan características macroscópicas similares a los del área de La Troya, distanciados 8 y $50 \mathrm{~km}$, respectivamente. Por su parte, las muestras provenientes de Guanchín ( $n=19$ ) presentan características diferenciales, ya que las que provienen de cotas superiores a los 2.000 m.snm presentan mayor fracción arenosa y menor plasticidad que las obtenidas en cota inferior. Estas últimas se asemejan en su textura a las procedentes de La Troya, distante $25 \mathrm{~km}$ aproximadamente. Todo el conjunto de las muestras del valle pertenece a la formación Calchaquense (Terciario).

\section{Metodología analítica}

Alcance y potencialidad del análisis por activación neutrónica

El principio del Análisis por Activación Neutrónica Instrumental (AAN) se basa en la utilización de algunas de las reacciones nucleares que ocurren cuando los isótopos estables que conforman los elementos químicos presentes en la muestra irradiada son bombardeados con neutrones (Arnold et al. 1999; Padilla 2001). La composición quí- mica de las rocas y sedimentos puede ser utilizada como base para un análisis numérico multivariado, ya que las relaciones de abundancia de los elementos minoritarios y de los elementos traza presentes en esos materiales deben reflejar las diferencias entre los ambientes geológicos de los que proceden (Bishop 1980). Para los sedimentos, incluyendo las materias primas utilizadas en la producción cerámica, su composición química está determinada por las rocas a partir de cuales se originaron, ya que la mayoría de los microelementos y elementos traza se concentran en las microestructuras cristalinas. La redistribución de estos elementos ocurre por la acción de diferentes procesos químicos y mecánicos durante los procesos de erosión, transporte y disposición. La clasificación de las muestras cerámicas en grupos estadísticamente diferenciables entre sí, a partir de las relaciones de abundancia observadas entre los elementos minoritarios y traza, parte de la premisa de que la composición química de la pasta de los tiestos está determinada principalmente por las características de las arcillas empleadas para su manufactura, definidas por Bishop y colaboradores (1982) como Unidades de Referencia de Composición Química de las Pastas.

Las pastas cerámicas son un sistema complejo constituido básicamente por dos componentes: minerales arcillosos e inclusiones no-plásticas o temperantes. Estas inclusiones pueden estar presentes en la composición original de la arcilla, o pueden ser adicionadas durante el proceso de manufactura. Esto determina que la interpretación de los resultados químicos no es lineal ni trivial, dado que las relaciones originales de concentración entre varios elementos en la arcilla pueden ser alteradas por la adición de temperante. Por lo tanto, es de vital importancia conocer la composición mineralógica de la muestra cerámica (Bishop 1980; Bishop et al. 1982; Bishop y Neff 1989; Neff 1992, entre otros). En general, las concentraciones de elementos traza tienden a ser menos afectados por la inclusión de temperantes como arena, calcita, fragmentos de rocas o vegetales, que por materiales volcánicos o inclusiones arcillosas (Bishop et al. 1982).

El empleo del AAN permite la caracterización de elementos que tienen una marcada diferenciación geoquímica durante el proceso de cristalización de las rocas ígneas, cuya meteorización dio ori- 
gen a las arcillas que luego fueron utilizadas para la manufactura de artefactos. Por lo tanto, conforman una herramienta útil para la diferenciación de los depósitos arcillosos, a través de elementos como las Tierras Raras (TTRR), Cromo (Cr), Torio $(\mathrm{Th})$, Escandio ( $\mathrm{Sc})$ y Hierro $(\mathrm{Fe})$, entre otros. Por su parte, los metales alcalinos, como Sodio $(\mathrm{Na})$, Potasio (K), Rubidio (Rb), Cesio (Cs), Calcio (Ca) y Bario (Ba), se encuentran en la estructura de los feldespatos, que a su vez constituyen los minerales más abundantes en la corteza terrestre. Además, altas concentraciones de los metales de transición, como el Cobalto (Co), Hierro (Fe), Hafnio (Hf), entre otros, pueden indicar la presencia de inclusiones metálicas en las pastas cerámicas producto de impurezas provenientes de sedimentos oxidados. De acuerdo con las características tecnológicas de la muestra analizada (ver más arriba) las inclusiones arcillosas se presentan en muy baja abundancia relativa.

\section{Preparación de muestras}

Para asegurar la homogeneidad de la muestra se siguió el siguiente procedimiento:

a) se utilizó un fragmento de tiesto de $2 \mathrm{~cm}^{2}$ (2-3 g), aproximadamente;

b) se limpió la superficie, raspándola con una lima de carburo de tungsteno, descartando el polvo resultante;

c) se molió el fragmento en un mortero de ágata y el polvo obtenido se secó en estufa a $105^{\circ} \mathrm{C}$ por 24 horas;

d) luego se dejó enfriar en un desecador, y

e) se conservó la muestra en un envase de vidrio hasta su análisis.

También se ensayó un método de preparación alternativo, basado en perforar la muestra con una broca de carburo de tungsteno. Se realizaron varias perforaciones sobre la sección transversal de la misma, obteniendo aproximadamente $300 \mathrm{mg}$ de polvo. Ambos métodos de preparación fueron probados sobre varios fragmentos de tamaño suficiente y se compararon los resultados analíticos, observando contaminación de Cobalto (Co) por uso de la mecha y que ésta rompía los trozos pequeños, impidiendo su perforación. Debido al predominio de tiestos de tamaño pequeño, se optó por adoptar el método de molienda para la preparación de todo el lote. Las muestras de los depósitos arcillosos fueron procesadas, sin tratamien- to previo, disgregándolas en mortero de ágata y secadas en estufa a $105^{\circ} \mathrm{C}$ por 24 horas.

Procedimientos analíticos

Las muestras fueron preparadas y analizadas mediante Análisis por Activación Neutrónica (AAN) instrumental en los laboratorios del Grupo Técnicas Analíticas Nucleares del Centro Atómico Ezeiza (Comisión Nacional de Energía Atómica). Se irradiaron masas de muestra de $100 \mathrm{mg}$, aproximadamente, envasadas en ampollas de cuarzo y colocadas en cápsulas de aluminio junto con materiales de referencia adecuados. Las irradiaciones se realizaron en el reactor RA-3 (flujo térmico $\left.3.10^{13} \mathrm{~cm}^{-2} \cdot \mathrm{s}^{-1} ; 4.5 \mathrm{Mw}\right)$ del Centro Atómico Ezeiza (Comisión Nacional de Energía Atómica), por cinco horas. Fueron hechas dos mediciones con aproximadamente siete y 30 días de decaimiento, determinando 22 elementos: As, $\mathrm{Ba}, \mathrm{Ce}$, $\mathrm{Co}, \mathrm{Cr}, \mathrm{Cs}, \mathrm{Eu}, \mathrm{Fe}, \mathrm{Gd}, \mathrm{Hf}, \mathrm{La}, \mathrm{Lu}, \mathrm{Nd}, \mathrm{Rb}, \mathrm{Sb}$, $\mathrm{Sc}, \mathrm{Sm}, \mathrm{Ta}, \mathrm{Tb}, \mathrm{Th}, \mathrm{U}$ y Yb. Las mediciones se realizaron usando detectores Ortec de Ge HP (30\% de eficiencia y resolución $1.8 \mathrm{keV}$ para el pico de $1332.5 \mathrm{keV}$ del Co-60), acoplados a un módulo buffer multicanal Ortec 919 y empleando el programa GammaVision para la adquisición de los datos. Para cuantificar, se empleó el material de referencia certificado NIST SRM 1633b Coal Fly Ash y las concentraciones fueron calculadas usando un programa desarrollado en el laboratorio.

\section{Control de calidad}

Los resultados del análisis por duplicado de aproximadamente el $10 \%$ de las muestras, mostraron un buen acuerdo, siendo la diferencia entre duplicados del orden de la desviación estándar. La reproducibilidad del método analítico fue probada analizando los materiales de referencia estándar NIST 2709 San Joaquín Soil, NIST 699 Brick Clay y USGS AGV, trazándose, además, cartas control. Los resultados del análisis de los materiales de referencia estándar San Joaquín Soil y Brick Clay fueron comparados con los producidos por los laboratorios de AAN del Instituto de Pesquisas Energéticas y Nucleares de Brasil y de la Comisión Chilena de Energía Nuclear y mostraron acuerdo con un $95 \%$ de confianza para $\mathrm{Ce}$, $\mathrm{Co}, \mathrm{Cr}, \mathrm{Cs}, \mathrm{Eu}, \mathrm{Fe}, \mathrm{Hf}, \mathrm{La}, \mathrm{Sc}, \mathrm{Sm}$, Th e Yb. Para realizar otro tipo de comparación, se dividieron cinco muestras cerámicas en cuatro fracciones, enviándolas a estos dos laboratorios y al de la 
Universidad de Pavia (Italia) y conservando las restantes para su análisis. Los resultados mostraron buen acuerdo entre los laboratorios. Un $67 \%$ de los elementos (Ce, Cr, Cs, Eu, Fe, Hf, K, Lu, $\mathrm{Na}, \mathrm{Rb}, \mathrm{Sc}, \mathrm{Sm}, \mathrm{Th}, \mathrm{U}, \mathrm{Yb}$ y Zn) mostró un error relativo menor al $10 \%$, para las cinco muestras. Para $25 \%$ de los elementos (As, Ba, Co, La, Sr y Ta) el error estuvo, para dos de las muestras, entre $10 \%$ y $15 \%$, y para el resto fue menor que el $10 \%$.

Tratamiento estadístico de los datos

Los elementos no son independientes entre sí, dado que existe correlación entre los que definen un factor. Las Tierras Raras están presentes generalmente en la masa arcillosa (barro), mientras que el Grupo Alcalino es una expresión de mezcla de fuentes de variación provenientes tanto del barro como de los temperantes. Estas situaciones determinan que se realice un exhaustivo tratamiento estadístico inductivo de cada elemento para conocer su distribución y correlaciones, previo a la realización del análisis multivariado. Este último se realizó por Componentes Principales (CP), utilizando el paquete estadístico SPSS 9.0. Los datos fueron transformados a base logarítmica, tratándose por matriz de covarianza y rotación Varimax. Aunque se determinaron 22 elementos para el análisis estadístico se seleccionaron aquellos:

a) cuyas mediciones tuvieran un error menor del $10 \%$;

b) que no se registraran datos faltantes o por debajo del límite de detección, y

c) con los que se contara con información suficiente sobre su comportamiento en la literatura especializada (Bishop 1980; Bishop et al. 1982; Bishop y Neff 1989; Neff 1992, entre otros).

Con base en lo expuesto, fueron seleccionados Ce, $\mathrm{Eu}, \mathrm{La}, \mathrm{Lu}, \mathrm{Sm}, \mathrm{Tb}, \mathrm{Yb}$ (Tierras Raras-Grupo III), Th (Actínido-Grupo III), Ba, Cs, Rb (AlcalinosGrupo I) y Sc, Hf, Co, Cr, Ta y Fe (Elementos de Transición). El Sb y U poseen las condiciones impuestas por los dos primeros criterios de selección mencionados, pero no cumplen con el tercero. Por ejemplo, el $\mathrm{Sb}$ puede sufrir potenciales pérdidas por volatilización durante la cocción, por lo que no es recomendable su análisis si se comparan concentraciones de muestras cocidas -tiestos- con no cocidas -arcillas e inclusiones minerales-, como es el caso que aquí se trata. Dado que las muestras de materia prima cerámica fue- ron analizadas sin tratamiento previo de elaboración de briquetas, se agregó un $10 \%$ a los valores de concentración de cada una de las muestras para compararlas con los datos de la matriz multielemental de los fragmentos cerámicos (R. Bishop, com. pers. 2000).

\section{Caracterización multielemental de las materias primas y fragmentos cerámicos}

Perfil químico multielemental de los depósitos arcillosos

Los análisis de activación neutrónica $(\mathrm{n}=54)$ reflejan claramente la diferenciación del perfil composicional multielemental entre las muestras de los depósitos arcillosos de la región puneña y del valle. Las relaciones de abundancia de los elementos minoritarios y traza presentes reflejan las diferencias entre los ambientes geológicos de los cuales proceden. Por su parte, algunas muestras procedentes del área de La Troya se diferencian del resto de sus pares, también procedentes del valle de Abaucán, a pesar que desde el punto de vista geológico pertenecen a una misma formación (Figura 4). Es interesante que algunas muestras del área puneña (Cazadero Grande) presentan un perfil químico similar a los depósitos del valle fuera del área de La Troya. Estos depósitos presentaban propiedades aptas para la manufactura cerámica. En la gráfica de cada factor se presenta a los elementos que aportan mayor carga

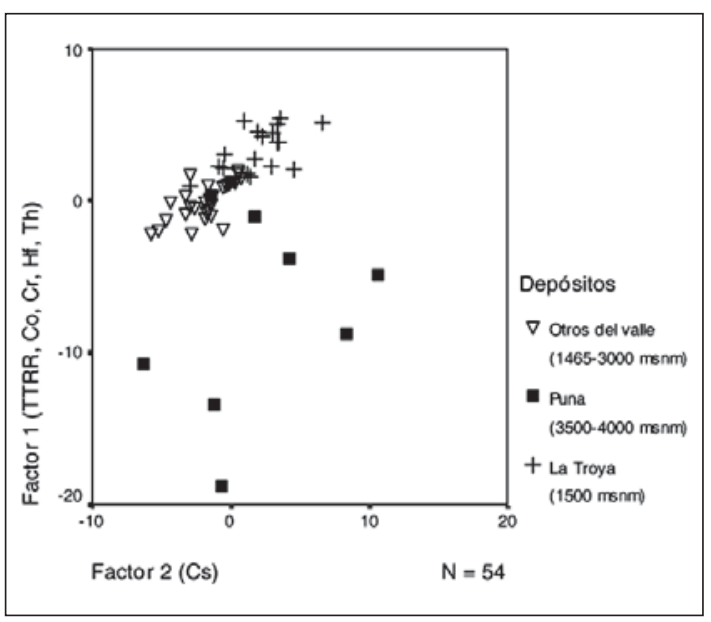

Figura 4. Representación en el espacio factorial de la composición multielemental de las muestras de arcilla procedentes del Valle mesotermal de Abaucán y la Puna de Chaschuil (\% varianza: $1 \mathrm{er} . \mathrm{C}=63.839$ y $2 \mathrm{do} . \mathrm{C}=15.780$. Varianza total explicada $=79.618 \%)$. 
para su definición, como así también la cantidad componentes y el porcentaje de varianza explicada, tanto a nivel individual como total.

Perfil químico multielemental de la muestra cerámica

El análisis estadístico multivariado define un perfil químico mayoritario para los tiestos adscriptos a los períodos Temprano y Medio procedentes de sitios arqueológicos de puna y valle (Figura 5), con excepción de algunos fragmentos. El resultado indica que los tiestos localizados dentro de la nube o grupo principal comparten la "firma química", interpretándose que fueron manufacturados con materias primas cerámicas procedentes de una misma área de aprovisionamiento. La excepción son los casos $\mathrm{N}^{\circ} 18,19,37,86,66,68$, 69, 70 y 71 que corresponden a tiestos Ciénaga y Aguada procedentes tanto de sitios del área puneña, como del valle (Figura 2). En estos casos, los perfiles composicionales son diferentes al resto de la muestra, infiriéndose que fueron manufacturados con materias primas diferentes.

El perfil multielemental de los tiestos analizados $(n=96)$ no covaría con el obtenido de las muestras de depósitos de materiales arcillosos procedentes del área puneña, conformando grupos separados dentro del espacio tridimensional. Sin embargo, cuando se realiza el tratamiento numérico multivariado relacionándolos con las 45 muestras procedentes de depósitos arcillosos del valle (La Troya, Guanchín, El Puesto y Colorado), se obtiene que el perfil químico de los tiestos de Puna y valle se superpone al de las arcillas del área de La Troya, separándose del resto de los depósitos muestreados (Figura 6).

Por último, los tiestos agrupados dentro de diferentes conjuntos tecnológicos (Figura 2) comparten mayoritariamente un mismo perfil químico, infiriéndose que las diferencias obedecen a sus contextos de uso pero no al de sus manufacturas, específicamente en las arcillas utilizadas (Figura 7). Es interesante observar que los tiestos que se apartan de la nube central, definida en el espacio factorial (Figura 5), mantienen las características tecnológicas a pesar de que no fueron manufacturados con materias primas cerámicas procedentes del área de La Troya, como así tampoco de las otras áreas relevadas y mencionadas en este trabajo (Figura 6).

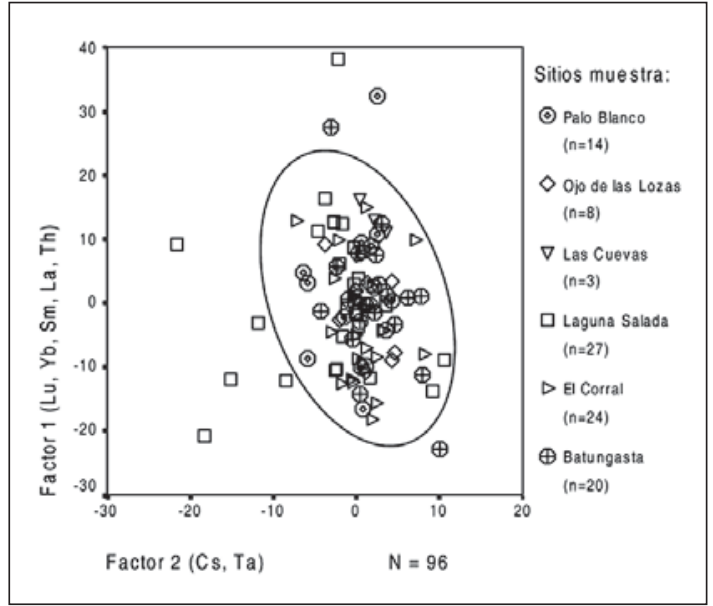

Figura 5. Representación en el espacio factorial de la composición multielemental de tiestos procedente de sitios arqueológicos localizados en Puna y valle (Tabla 3) (\% Varianza: 1er. $\mathrm{C}=28.00 ; 2$ do $. \mathrm{C}=8.311$; 3er. $\mathrm{C}=9.903$; 4to $. \mathrm{C}=8.355$ y 5 to. $\mathrm{C}=7.299$. Varianza Total explicada $=61.868 \%$ ).

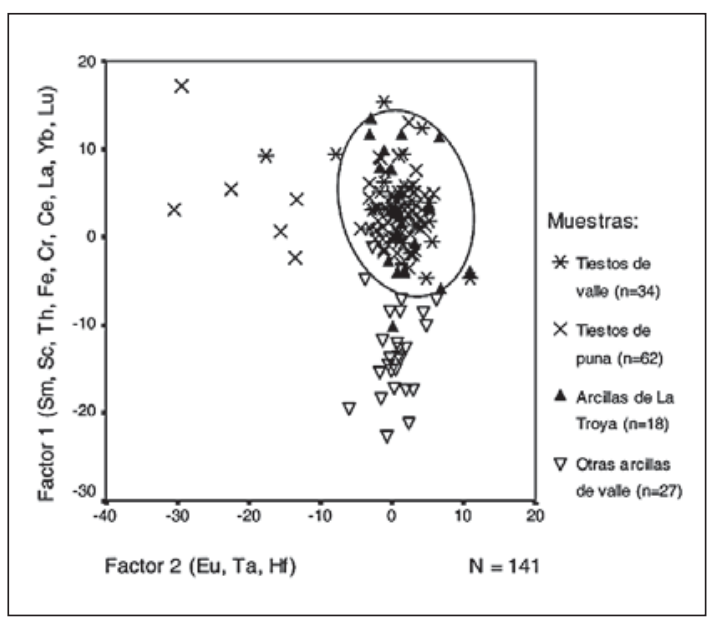

Figura 6. Representación en el espacio factorial de la composición multielemental de los tiestos de Puna y valle, y las arcillas de valle (\% Varianza: 1 er. $\mathrm{C}=49.972 ; 2$ do.C $=10.544$ y 3er.C $=5.592$. Varianza Total explicada $=66.107 \%)$.

En resumen, los resultados del análisis por activación neutrónica realizados sobre la muestra de tiestos asignados a los períodos Temprano y Medio, y de los depósitos arcillosos permite decir que:

a) Los depósitos arcillosos procedentes del área de Puna (3.500-4.000 m.snm) y valle (3.000-1.465 $\mathrm{m} . \mathrm{snm})$, presentan perfiles composicionales diferentes que se manifiestan a nivel macrorregional, como así también a través de variaciones interregionales (Figura 4). 


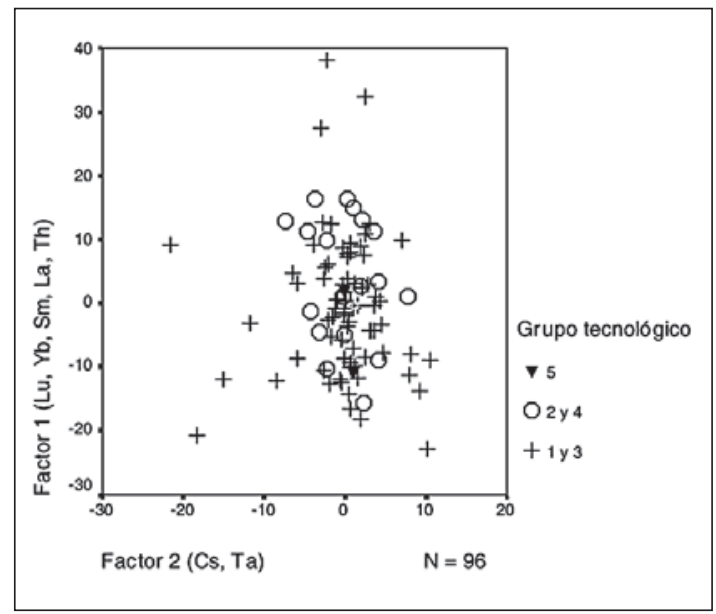

Figura 7. Representación en el espacio factorial de los perfiles multielementales de los tiestos de Puna y valle en función de los grupos (clusters) tecnológicos definidos (ver Figura 2).

b) Los tiestos de los períodos Temprano y Medio procedentes de instalaciones localizadas en puna (4.000 m.snm) y el Bolsón de Fiambalá (1.500 m.snm), separadas por una distancia de $100 \mathrm{~km}$ lineales, aproximadamente, presentan perfiles multielementales homólogos para el $91 \%$ de los casos analizados $(n=96)$, separándose el resto del perfil químico compartido (Figura 5).

c) El perfil composicional multielemental de los tiestos de Puna y valle para los períodos Temprano y Medio no guarda relación con el de los depósitos arcillosos muestreados en el área puneña (Cazadero, Las Lozas y San Francisco).

d) Los tiestos de Puna y valle adscritos a los períodos Temprano y Medio y los depósitos arcillosos procedentes del área de La Troya, comparten un perfil composicional multielemental, diferenciándose netamente de las otras arcillas analizadas procedentes también del valle mesotermal (El Puesto, Colorado y Guanchín) (Figura 6).

e) Algunos casos de la muestra artefactual cerámica guarda similitud tecnológica con el resto de la muestra, pero fueron manufacturados con materias primas localizadas en áreas fuera de los espacios muestreados (Figura 7).

\section{Conclusiones}

La interrelación de los resultados obtenidos por la vía de la caracterización multielemental, tanto de los tiestos como de los depósitos de materias primas cerámicas, más los aportados por los análisis tecnológicos y estilísticos, conforman el soporte para la discusión de las relaciones regionales entre los pisos puneños de Chaschuil y su relación con el valle mesotermal del Bolsón de Fiambalá, en el Abaucán. Sin embargo, la interrelación de factores analíticos y tecnológicos no explica por sí misma el problema de la distribución de los artefactos cerámicos, debiéndose tener en cuenta los factores socioculturales por los cuales los objetos arribaron a su destino.

La variabilidad tecnológica de los tiestos (ver Figura 2) se relaciona mayoritariamente con un perfil químico homogéneo (ver Figura 7), ya que a pesar de las diferencias mineralógicas de la composición del antiplástico, su representatividad y tamaño, la muestra fue manufacturada con arcillas del área de La Troya (1.500 m.snm), guardando entre sí un perfil composicional multielemental similar. El área puneña presenta materias primas de buena calidad para la manufactura cerámica, especialmente en Cazadero Grande (3.500 m.snm) pero no fueron utilizadas, habiéndose seleccionado las localizadas en el Bolsón de Fiambalá, específicamente en el área de La Troya. El valle, particularmente, ofrece las condiciones necesarias para la producción cerámica, principalmente por la disponibilidad y abundancia de materias primas, de combustibles y condiciones climáticas óptimas que permiten sostener una producción anual (Ratto et al. 2002). La Puna de Chaschuil también ofrece especies vegetales con usos energéticos para combustión pero ninguna es apta para mantener el calor constante a altas temperaturas como es necesario para la producción cerámica (Pérez de Micou y Ratto 2002).

El aprovisionamiento de materias primas cerámicas en el área de La Troya durante la etapa Formativa tiene especial relevancia por su relación con el sitio arqueológico Batungasta (1.500 m.snm). Por estudios recientes se conoce que este sitio funcionó como un centro de producción y distribución de bienes cerámicos para abastecer a las instalaciones puneñas de Chaschuil en tiempos incaicos (Ratto et al. 2002). Los procesos de reclamación en el sitio se materializan hoy día por el testimonio arquitectónico y artefactual que da cuenta de la presencia inca e hispano-indígena. Sin embargo, la abundancia de material con estilos cerámicos propios de las etapas Formativas 
(Ciénaga, Saujil, Aguada, entre otros) permite pensar en una larga ocupación de ese espacio por sociedades con organizaciones socioeconómicas y políticas diferentes. Hasta el momento, hemos excavado dos de las 27 estructuras de combustión (hornos) para la manufactura cerámica localizadas en la periferia del sitio Batungasta, las que varían en sus formas y tamaños. A pesar que el material cerámico recuperado responde a estilos del Período Tardío (preinca) e Inca, es posible que el avance de los trabajos reporte sobre su uso en tiempos de sociedades formativas. Por lo tanto, es factible plantear que durante la etapa Formativa, entre el 550 al 1.160 de la era, el área de La Troya no sólo fue el lugar de aprovisionamiento de materias primas sino también de manufactura cerámica para proveer a las instalaciones localizadas en pisos puneños. Lo concreto es que tanto la evidencia arquitectónica y/o artefactual como los resultados por activación neutrónica están indicando la reproducción de prácticas que incorporan el uso de los mismos espacios del valle y de la Puna en distintos momentos de la historia regional. Es muy probable que la abundancia de camélidos silvestres y las altas cumbres cordilleras fueran valorizados tanto desde la esfera económica como ideológica de las sociedades prehispánicas en el tiempo, teniendo este aspecto mejor calibrado para tiempos incaicos (Ratto y Orgaz 1997 y 2001).

La distancia existente entre una y otra área, de aproximadamente $100 \mathrm{~km}$ lineales, hace pensar en los mecanismos y características del tráfico, como así también en su evolución en el tiempo, dado que un comportamiento similar se observa para tiempos incaicos (Plá y Ratto 2000). Un posible mecanismo de tráfico es el planteado por los modelos caravaneros (Núñez y Dillehay 1979; Berenguer 1994; Núñez 1994). La idea subyacente es que el tráfico formó parte de la economía política de los señoríos centro-sur andinos sobre la base de un tráfico familiar o de subsistencia que se fue socializando y especializándose hasta ser incorporado al control comunal y, posteriormente, por autoridades supracomunitarias (Berenguer 1994). En este contexto, la actividad caravanera excede la complementariedad ecológica para acceso a recursos diversos y se constituye en una actividad que promueve, mantiene y refuerza la trama de relaciones socioeconómicas y políticas a nivel macrorregional (Berenguer 1994; Núñez 1994; Pérez Gollán et al. 1996-1997).

De esta manera, la región de Chaschuil se presenta como un corredor de circulación de energía, bienes e información desde tiempos de las sociedades agroalfareras hasta los momentos de ocupación incaica, constituyéndose en una de las múltiples vías o rutas de circulación que integraron los territorios del este con el oeste, de uno y otro lado de la cordillera andina.

Agradecimientos A Néstor Kriscautzky, Andrés Laguens y José Togo por la paciencia para contestar nuestras consultas para la clasificación de la muestra cerámica. Los análisis de activación neutrónica fueron realizadas en el marco del Programa Nuclear Analytical Techniques in Archaeological Investigations (ARG 93-93) financiado por la Agencia Internacional de Energía Atómica, Viena.

\section{REFERENCIAS CITADAS}

ACEÑOLAZA, F. y J. TOSELLI, 1981. Geología del Noroeste Argentino. Universidad Nacional de Tucumán. Facultad de Ciencias Naturales, San Miguel de Tucumán.

ARGERICH, F., 1976. Fisiografía de la Provincia de Catamarca. Publicación de la Dirección Provincial de Cultura, Catamarca.

ARNOLD, D., H. NEFF, R. BISHOP y M. GLASCOC, 1999. Testing interpretative assumptions of Neutron Activation Analysis. En Material meaning. Critical approaches to the interpretation of material culture, E. Chilton (Ed.), pp. 61-84. The University of Utah Press, Salt Lake.
ASSANDRI, S. y S. JUEZ, 1996-1997. Organización espacial de los asentamientos en el valle de Ambato, Período de Integración Regional. Shincal 6: 71-82.

BERENGUER, J., 1994. Asentamientos, caravaneros y tráfico de larga distancia en el norte de Chile: El caso de Santa Bárbara. En De costa a selva. Producción e intercambio entre los pueblos agroalfareros de los Andes Centro-Sur, M. E. Albeck (Ed.), pp. 17-50. Instituto Interdisciplinario Tilcara, Facultad de Filosofía y Letras (UBA), Tilcara. 
BISHOP, R., 1980. Aspects of ceramic compositional modeling. En Models and methods in regional exchange, R. E. Fry (Ed.), pp. 47-65. SAA Paper 1, Society for American Archaeology, Washington D. C.

BISHOP, R., R. RANDS y G. HOLLEY, 1982. Ceramic compositional analysis in archaeological perspective. En Advances in archaeological method and theory, $\mathrm{M}$. Schiffer (Ed.), 5: 275-230. Academic Press, Nueva York.

BISHOP, R. L. y H. NEFF, 1989. Compositional data analysis in archaeology. En Archaeological chemistry IV, R. O. Allen (Ed.), pp. 57-86. Advances in Chemistry Series 220, American Chemical Society, Washington, D. C.

BRODA, J., 2000. Ritos Mexicas en los cerros de la cuenca: Los sacrificios de niños. En La montaña en el paisaje ritual, J. Broda, S. Iwaniszawski e I. Montero (Eds.), pp. 279-288. Universidad Nacional Autónoma de México, México D. F.

CABRERA, A. y A. WILLINK, 1973. Biogeografía de América Latina. Serie de Biología. Monografía 13. Secretaría General de la Organización de los Estados Americanos, Washington D. C.

CASTILLO, G., H. NIEMEYER y M. CERVELLINO, 19961997. Indicadores, alcances y perspectivas de influencias Aguada en el valle de Copiapó. Shincal 6: 193-212.

COSTEllO, J., 1993. Geografía de Catamarca. Editorial Sarquis, Catamarca.

CRIADO BOADO, F., 1997. Introduction: Combining the different dimensions of cultural space: Is a total archaeology of landscape possible? En Landscape, Archaeology, Heritage, F. Criado y C. Parcero (Eds.), pp. 5-9, Capa 2. Universidad de Santiago de Compostela, Santiago de Compostela.

CRISCI, J. V. y M. F. LOPEZ, 1983. Introducción a la teoría y práctica de la taxonomía numérica. Monografía 26. Serie Biología. Secretaría General de la Organización de los Estados Americanos, Washington D. C.

CRUMLEY, C. y V. MARQUARDT, 1991. Landscape: A unifying concept in regional analysis. En Interpreting space: GIS and archaeology, K. Allen, S. Green y E. Zubrow (Eds.), pp. 73-79. Taylor and Francis, Londres.

DE LA FUENTE, G., 1997. Estudios comparativos de materias primas cerámicas entre la región de Chaschuil (Puna) y la cuenca del río La Troya (Bolsón de Fiambalá). En Informe de Avance Proyecto Arqueológico ChaschuilPACh.1995-1998. Secretaría de Ciencia y Técnica. Tomo I. Universidad Nacional de Catamarca, Catamarca.

GONZALEZ, A., 1977. Arte precolombino de la Argentina. Introducción a su historia cultural. Editorial Valero, Buenos Aires.

_-1999. La Cultura de La Aguada y el Período Formativo. En Formativo sudamericano, P. Ledergerber-Crespo (Ed.), pp. 285-301. Ediciones ABYA-YALA, Cuenca.
GONZALEZ, A. y J. PEREZ GOLLAN, 1976. Argentina indígena, víspera de la conquista. Editorial Paidós, Buenos Aires.

KRISCAUTZKY, N., 1996-1997. Nuevos aportes en la arqueología del valle de Catamarca. Shincal 6: 27-34.

LANATA, J. L., 1997. Los componentes del registro arqueológico. Revista de Arqueología Americana 13: 153-165.

LIZZIE, J. M., H. NEFF, y M. D. GLASCOCK, 1995. Clay acquisition and vessel distribution patterns: Neutron Activation Analysis of Late Windsor and Shantock Tradition Ceramics from Southern New England. American Antiquity 60 (3): 515-530.

LUNA, M. B., 1996. Análisis tecnológico de instrumentos y núcleos arqueológicos en subcuencas hídricas de la Puna Meridional catamarqueña (Chaschuil, Tinogasta, Catamarca). Tesis de Licenciatura. Escuela de Arqueología. Universidad Nacional de Catamarca, Catamarca.

MARTINEZ CARRETERO, E., 1995. La Puna argentina: Delimitación general y división en Distritos florísticos. Boletín Sociedad Argentina de Botánica 31 (1-2): 27-40.

MORLANS, M. C., 1985 Ms. Regiones naturales de Catamarca: Provincias geológicas y Provincias fitogeográficas. Cátedra de Ecología Agraria. Universidad Nacional de Catamarca, Catamarca.

MORLANS, M. C. y B. GUICHON, 1995. Reconocimiento ecológico de la Provincia de Catamarca. Revista de Ciencia y Técnica de la Secretaría de Investigación (UNCa) 1: $15-51$.

NAMI, H., 1992. El subsistema tecnológico de la confección de instrumentos líticos y la explotación de los recursos del ambiente: Una vía de aproximación. Shincal 2: 33-53.

NAVARRO, H., 1990. Catamarca: Hacia un estudio integral de su geografía. Edición del autor, Catamarca.

NEFF, H. (Ed.), 1992. Chemical characterization of ceramic paste in archaeology. Monographs in World Archaeology 7. Prehistory Press, Madison.

1998. Units in chemistry-based ceramic provenance investigations. En Unit Issues in Archaeology, A. Ramenofsky y A. Steffen (Eds.), pp. 115-128. University of Utah Press, Salt Lake.

NIEMEYER, H., 1994. Pasos cordilleranos y contactos entre los pueblos del Norte Chico de Chile y el Noroeste Argentino. En La Cordillera de Los Andes: Rutas de encuentros, Museo Chileno de Arte Precolombino, pp. 2337. Santiago.

NIEMEYER, H., M. CERVELLINO y G. CASTILlO, 1997.Culturas Prehistóricas del Copiapó. Museo Regional de Atacama, Copiapó.

NOETINGER, M., 1996 Ms. Estructura de la vegetación y modelo de depositación-dispersión polínica en el valle 
de Chaschuil, Catamarca. Informe Final Beca Posdoctoral al CONICET.

NUÑEZ, L., 1994. Cruzando la cordillera por el norte: Señoríos, caravanas y alianzas. En La Cordillera de Los Andes: Rutas de encuentros, Museo Chileno de Arte Precolombino, pp. 9-21. Santiago.

-1999. Fase Tilocalar: Nuevas evidencias formativas en la Puna de Atacama (norte de Chile). En Formativo sudamericano, P. Ledergerber-Crespo (Ed.), pp. 227-242. Ediciones ABYA-YALA, Cuenca.

NUÑEZ, L. y T. DILLEHAY, 1979. Movilidad giratoria, armonía social y desarrollo en los Andes Meridionales: Patrones de tráfico e interacción económica. Universidad del Norte, Antofagasta.

NUÑEZ REGUEIRO, V. y M. TARTUSI, 1993. Los centros ceremoniales del N.O.A. Publicaciones del Instituto de Arqueología 5: 4-49.

OLIVERA, D., 2001 Sociedades agropastoriles tempranas: El Formativo inferior del Noroeste Argentino. En Historia argentina prehispánica, E. Berberian y A. Nielsen (Eds.), pp. 83-125. Editorial Brujas, Buenos Aires.

ORGAZ, M., 1995. Presencia incaica en los Andes Meridionales. Caso de estudio en la cabecera norte del valle de Chaschuil (Tinogasta, Catamarca). Tesis de Licenciatura de la Escuela de Arqueología de la Universidad Nacional de Catamarca, Catamarca.

PADILLA, R., 2001. El análisis por activación neutrónica. En Las técnicas analíticas nucleares en el estudio y conservación del patrimonio cultural: Alcances y potencialidades, pp. 16-21. CEADEN, La Habana.

PEREZ GOLLAN, J. A., 1994a. El proceso de integración en el valle de Ambato: Complejidad social y sistemas simbólicos. Rumitacana 1 (1): 33-41.

_1994b. Los sueños del jaguar. Imágenes de la Puna y la Selva argentina. Museo Chileno de Arte Precolombino, Santiago.

PEREZ GOLLAN, J. A., y O. HEREDIA, 1987. Hacia un replanteo de La Aguada. Cuadernos 12: 161-178.

PEREZ GOLlan, J. A., M. BONNIN, A. LAGUENS, S. ASSANDRI, L. FEDERICI, M. GUDEMOS, J. HIERLING y S. JUEZ, 1996-1997. Proyecto arqueológico Ambato: Un estado de la cuestión. Shincal 6:115-123.

PEREZ DE MICOU, C. y N. RATTO, 2002. Las plantas silvestres como recursos en regiones áridas (Puna y Patagonia). Actas de las IV Jornadas de Arqueología de Patagonia, Buenos Aires (en prensa).

PLA, R. y N. RATTO, 2000. Provenience archaeological studies of ceramic raw material and artifacts using instrumental Neutron Activation Analysis: The cases of Chaschuil and Bolsón de Fiambalá (Catamarca, Argentina). En Nuclear analytical techniques in archaeological investigations. Report Series 416: 7-22. International Atomic Energy Agency, Viena.

RATTO, N., 1995 Ms. Proyecto arqueológico Chaschuil. Pach 94. Informe Final Proyectos de Investigación y Desarro1lo. SECYT-UNCa, Catamarca.

1996 Ms. Informe de Avance del Proyecto de Rescate Arqueológico de Batungasta, PRABat, (Tinogasta, Catamarca). Secretaría de Ciencia y Tecnología. Universidad Nacional de Catamarca, Catamarca.

- 1997 Ms. Informe de Avance Proyecto Arqueológico Chaschuil, PACh.1995-1998. Presentado a la Secretaría de Ciencia y Técnica. Tomos I y II. Universidad Nacional de Catamarca, Catamarca.

1998. Distributional archaeology and paleoecology in the southern Puna, Catamarca, Argentina: Preliminary results. En Proceeding XIII Congress of the International Union of Prehistoric and Protohistoric Sciences, C. Arias, A. Bietti, L. Castelletti, C. Peretto (Eds.), pp. 261-270, Sections 1. ABACO, Forli.

2000. La estructura del registro arqueológico en la cuenca superior del valle de Chaschuil (Depto. Tinogasta, Catamarca). Arqueología 10: 39-78.

2003. Estrategias de caza y propiedades del registro arqueológico en la Puna de Chaschuil. Tesis presentada para optar al grado de Doctor de la Facultad de Filosofía y Letras de la Universidad de Buenos Aires, Buenos Aires.

RATTO, N. y M. ORGAZ, 1997. La cacería en los Andes: Registro material del chaku en la Puna Meridional catamarqueña (Cazadero Grande, Depto. Tinogasta, Catamarca, Argentina). En Resúmenes del XIV Congreso Nacional de Arqueología Chilena. Anexo 1 Contribución Arqueológica, pp. 132-133. Museo Regional de Atacama, Copiapó.

_2000 Ms. La ocupación inca en la Puna Meridional catamarqueña: El caso de la cuenca superior del valle de Chaschuil (Depto. Tinogasta, Catamarca, Argentina).

-2001. Cacería comunal de camélidos en los Andes: El caso de las macroestructuras La Lampaya y El Matambre en Cazadero Grande (Chaschuil, Depto. Tinogasta, Catamarca, Argentina). Arqueología 12 (en prensa).

RATTO, N., M. ORGAZ y R. PLA, 2002. Producción y distribución de bienes cerámicos durante la ocupación inca entre la región puneña de Chaschuil y el valle de Abaucán (Depto. Tinogasta, Catamarca). Relaciones de la Sociedad Argentina de Antropología XXVII (en prensa).

ROSSIGNOL, J. y L. WANDSNIDER (Eds.), 1992. Space, time, and archaeological landscapes. Plenum Press, Nueva York y Londres.

SCALA, C., M. BORTOLOZZI y M. TADDEI, 1995a. Stima della densitá 'di vicogna e guanaco nel bacino del río Cazadero (Ande di Catamarca, Argentina). Valutazione quantitativa del differenziamento eto-ecologico in un 
ecosistema andino. Working Paper 95.8. Universidad de Siena, Siena.

SCALA, C., L. CASINI y L. D'ALESSANDRO, 1995 b. Ulteriore stima della densita' di vicogna e di guanaco nel bacino del río Cazadero (ande di Catamarca, Argentina). Valutazione quantitativa del differenziamento etoecologico in un ecosistema andino. Working Paper 95.18. Universidad de Siena, Siena.

SCHIFFER, M., 1987. Formation processes of the archaeological record. University of Utah Press, Salt Lake.

SEMPE, M. C., 1976. Arqueología del Valle de Abaucán. Tesis Doctoral de la Facultad de Ciencias Naturales y Museo (UNLP), La Plata.

_ 1977a. Las culturas agroalfareras prehispánicas del valle de Abaucán (Tinogasta, Catamarca). Relaciones de la Sociedad Argentina de Antropología (NS) T XI: 55-68.

_1977b. Batungasta: Un sitio tardío e incaico en el valle de Abaucán (Depto. Tinogasta, Catamarca) y su signifi- cación etnohistórica. Actas y Memorias (2da. Parte) IV Congreso Nacional de Arqueología Argentina, pp. 69-83. San Rafael.

SHENNAN, S., 1992. Arqueología cuantitativa. Editorial Crítica, Barcelona.

TURNER, J. C., 1967. Descripción geológica de la Hoja 13 b Chaschuil. Boletín 106. Instituto Nacional de Geología y Minería, Buenos Aires.

WANDSNIDER, L. y E., CAMILLI, 1992. The character of surface archaeological deposit and its influence on survey accuracy. Journal of Field Archaeology 19 (2): 169-188.

YACOBACCIO, H., 1991. Sistemas de asentamiento de cazadores-recolectores tempranos de los Andes Centro-Sur. Tesis Doctoral de la Facultad de Filosofía y Letras, Universidad de Buenos Aires, Buenos Aires.

-1994. Biomasa animal y consumo en el PleistocenoHoloceno surandino. Arqueología 4: 43-72. 
